\title{
The Role of Nuclear Medicine in the Clinical Management of Benign Thyroid Disorders, Part 2: Nodular Goiter, Hypothyroidism, and Subacute Thyroiditis
}

\author{
Giuliano Mariani ${ }^{1}$, Massimo Tonacchera ${ }^{2}$, Mariano Grosso $^{3}$, Emilio Fiore $^{2}$, Pierpaolo Falcetta ${ }^{2}$, Lucia Montanelli ${ }^{2}$, \\ Brunella Bagattini ${ }^{2}$, Paolo Vitti ${ }^{2}$, H. William Strauss ${ }^{4}$ \\ ${ }^{1}$ Regional Center of Nuclear Medicine, Department of Translational Research and Advanced Technologies in Medicine and Surgery, \\ University of Pisa, Pisa, Italy; ${ }^{2}$ Endocrinology and Metabolism Unit, Department of Clinical and Experimental Medicine, University of \\ Pisa, Pisa, Italy; ${ }^{3}$ Regional Center of Nuclear Medicine, University Hospital of Pisa, Pisa, Italy; and 4Molecular Imaging and Therapy \\ Service, Memorial Sloan Kettering Cancer Center, New York, New York
}

Learning Objectives: On successful completion of this activity, participants should be able to have acquired knowledge on (1) the clinical manifestations, underlying pathophysiology, imaging modalities, and therapy of non-toxic nodular goiter; (2) the clinical manifestations, underlying pathophysiology, imaging modalities, and therapy of hypothyroidism; and (3) on the clinical manifestations, underlying pathophysiology, imaging modalities, and therapy of subacute thyroiditis.

Financial Disclosure: The authors of this article have indicated no relevant relationships that could be perceived as a real or apparent conflict of interest.

CME Credit: SNMMI is accredited by the Accreditation Council for Continuing Medical Education (ACCME) to sponsor continuing education for physicians. SNMMI designates each JNM continuing education article for a maximum of 2.0 AMA PRA Category 1 Credits. Physicians should claim only credit commensurate with the extent of their participation in the activity. For CE credit, SAM, and other credit types, participants can access this activity through the SNMMI website (http://www. snmmilearningcenter.org) through July 2024.

Part 2 of this series of Continuing Education articles on benign thyroid disorders deals with nodular goiter, hypothyroidism, and subacute thyroiditis. Together with Part 1 (which dealt with various forms of hyperthyroidism), this article is intended to provide relevant information for specialists in nuclear medicine dealing with the clinical management of patients with benign thyroid disorders, the primary audience for this series. Goiter, an enlargement of the thyroid gland, is a common endocrine abnormality. Constitutional factors, genetic abnormalities, or dietary and environmental factors may contribute to the development of nodular goiter. Most patients with nontoxic nodular goiter are asymptomatic or have only mild mechanical symptoms (globus pharyngis). Workup of these patients includes measurement of thyroid-stimulating hormone, free triiodothyronine, free thyroxine, thyroid autoantibodies, ultrasound imaging, thyroid scintigraphy, and fine-needle aspiration biopsy of nodules with certain ultrasound and scintigraphic features. Treatment for multinodular goiter includes dietary iodine supplementation, surgery, radioiodine therapy (to decrease thyroid size), and minimally invasive ablation techniques. Hypothyroidism ranges from rare cases of myxedema to more common mild forms (subclinical hypothyroidism). Primary hypothyroidism often has an autoimmune etiology. Clinical presentations differ in neonates, children, adults, and elderly patients. Work-up includes thyroid function tests and ultrasound imaging. Nuclear medicine is primarily used to locate ectopic thyroid tissue in congenital hypothyroidism or to detect defects in iodine organification with the perchlorate discharge test. Treatment consists of thyroid replacement therapy with L-thyroxine, adjusting the daily dose to the individual patient's metabolic and hormonal requirements. Subacute thyroiditis is a selflimited inflammatory disorder of the thyroid gland, often associated with painless or painful swelling of the gland and somatic signs or symptoms. Inflammation disrupts thyroid follicles resulting in a rapid release of stored thyroxine and triiodothyronine causing an initial thyrotoxic phase,

Received Oct. 19, 2020; revision accepted Jan. 27, 2021.

For correspondence, contact Giuliano Mariani (giuliano.mariani@med.unipi.it). Published online Feb. 2, 2021

COPYRIGHT @ 2021 by the Society of Nuclear Medicine and Molecular Imaging. often followed by transient or permanent hypothyroidism. Although subacute thyroiditis is often related to a viral infection, no infective agent has been identified. Subacute thyroiditis may be caused by a viral infection in genetically predisposed individuals. Work-up includes lab tests, ultrasound imaging, and radionuclide imaging. Thyroid scintigraphy demonstrates different findings depending on the phase of the illness, ranging from very low or absent tracer uptake in the thyroid gland in the hyperthyroid phase to a normal appearance in the late recovery phase. Since subacute thyroiditis is self-limited, treatment is directed toward relief of pain. High-dose nonsteroidal antiinflammatory drugs are usually the first-line treatment. If severe pain persists, a course of corticosteroids may be necessary. Permanent hypothyroidism develops in up to $15 \%$ of patients with subacute thyroiditis, even more than $1 \mathrm{y}$ after presentation.

Key Words: diffuse and nodular goiter: primary autoimmune hypothyroidism; subacute, destructive thyroiditis; lab tests for benign thyroid disorders; ultrasound imaging; radionuclide imaging

\section{J Nucl Med 2021; 62:886-895}

DOI: 10.2967/jnumed.120.251504

$\mathbf{T}$ his is Part 2 of the continuing education series on benign thyroid disease. Part 1 of this series, published in the March 2021 issue of The Journal of Nuclear Medicine (1), dealt with hyperthyroid states due to Graves disease, toxic multinodular goiter, toxic adenoma, and destructive thyroiditis. This Part 2 paper deals with nodular goiter, hypothyroidism, and subacute thyroiditis. These two articles provide relevant information for specialists in nuclear medicine dealing with the clinical management of patients with benign thyroid disorders.

\section{GOITER AND THYROID NODULES}

\section{Epidemiology and Clinical Presentation}

Goiter, an enlargement of the thyroid gland $\left(>20 \mathrm{~cm}^{3}\right.$ in men and $>15 \mathrm{~cm}^{3}$ in women) with or without nodules, is one of the most 


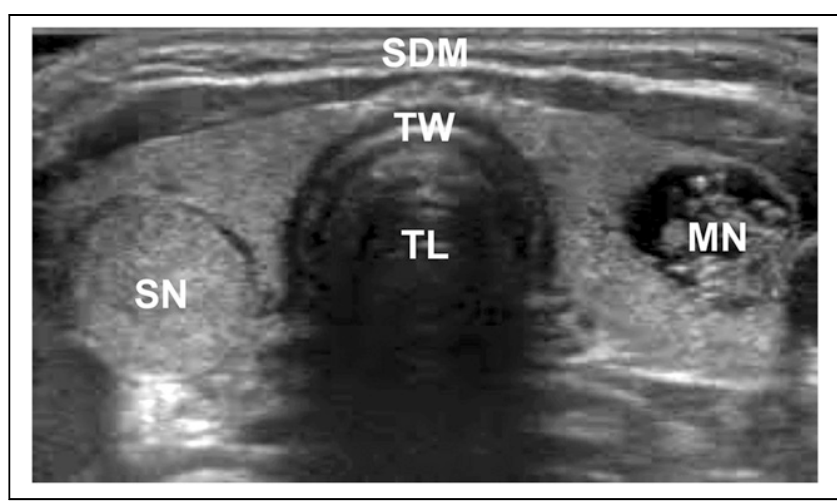

FIGURE 1. Ultrasonography of multinodular thyroid gland (axial view). Right lobe shows single well-defined isoechoic nodule surrounded by hypoechoic rim (halo sign). Left lobe shows mixed nodule, cystic with echogenic solid component. $\mathrm{MN}=$ mixed nodule in left lobe; SDM = skin, dermis, and muscles forming superficial layer in neck; $\mathrm{SN}=$ solid nodule in right lobe; TL $=$ tracheal lumen; $\mathrm{TW}=$ tracheal wall.

common endocrine abnormalities. If thyroid function is normal, the goiter is described as nontoxic and nodular. The incidence of new nodular goiter cases in adults in the United States is $0.1 \%-1.5 \%$ of the general population per year (2). Goiter is more common in women than men (3). In areas of iodine deficiency, the incidence of thyroid nodules increases with age (without a sex-related difference) (4), whereas in iodine-sufficient areas the prevalence of nodular goiter decreases with age (5). Constitutional factors, genetic abnormalities, and dietary or environmental factors may contribute to the development of nodular goiter (3-6). Thyroid nodules may become autonomous, possibly evolving to cause thyrotoxicosis.

Clinically, goiter is categorized as diffuse goiter, solitary nodular goiter, or the most prevalent phenotype, multinodular goiter. Most patients with nontoxic nodular goiter are asymptomatic or have mild mechanical symptoms (globus pharyngis). Nodular goiter is often discovered incidentally during an ultrasound scan performed for other reasons. Symptoms of compression of the trachea, esophagus, great vessels, and recurrent laryngeal nerve in the presence of a goiter suggest that a long-term nodular goiter has partially migrated to the retrosternal or upper mediastinal regions.

\section{Etiology and Pathophysiology}

Worldwide, the most important environmental factor for goiter development is iodine deficiency $(3,4,7)$, and there is an inverse correlation between iodine intake and the prevalence of goiter $(8)$. Other factors include genetic susceptibility, female sex, increased body mass, and smoking $(7,9,10)$. Smoking promotes goiter development, probably because of the thiocyanate in cigarette smoke, which block iodination, leading to a compensatory increase in secretion of the thyroid-stimulating hormone (TSH) (11).

\section{Lab Tests}

$\mathrm{TSH}$, free thyroxine (T4), and free triiodothyronine (T3) should be measured. If the TSH is reduced and free T4 and/or free T3 is elevated, the patient has progressed to a toxic nodular goiter. In iodinedeficient areas, nodules may become autonomous because of persistent stimulus from elevated TSH due to reduced thyroid hormone production.

The presence of antibodies recognizing thyroid peroxidase, thyroglobulin, or the TSH receptor suggests the coexistence of Hashimoto disease or Graves disease.

\section{Ultrasound Imaging}

Ultrasonography is used to determine thyroid volume and the echogenicity, margins, shape, content, calcifications, vascularity, size, and elasticity of nodules, in addition to the status of regional lymph nodes (Fig. 1; Supplemental File 1; supplemental materials are available at http://jnm.snmjournals.org). The European Thyroid Association (12), the American College of Radiology (13), and the American Thyroid Association (14) have issued guidelines (with slight differences) for stratifying the risk of malignancy for thyroid nodules according to the so-called Thyroid Imaging Reporting and Data System (TI-RADS). The ultrasound-based criteria (Tables 1 and 2) stratify thyroid nodules into 5 categories of risk of malignancy, a change from prior consensus guideline that stratified the ultrasound risk of malignancy into 3 categories (15); examples of thyroid nodules with different European Thyroid Association Thyroid Imaging Reporting and Data System (EU-TIRADS) scores are presented in Supplemental File 2. About $50 \%$ of the nodules

TABLE 1

TI-RADS Ultrasound Features of Thyroid Nodules

\begin{tabular}{|c|c|c|c|c|c|c|c|c|c|}
\hline \multicolumn{2}{|l|}{ Composition* } & \multicolumn{2}{|c|}{ Echogenicity ${ }^{\star}$} & \multicolumn{2}{|c|}{ Shape* } & \multicolumn{2}{|c|}{ Margins $^{*}$} & \multicolumn{2}{|c|}{ Echogenic foci ${ }^{\dagger}$} \\
\hline Description & Points & Description & Points & Description & Points & Description & Points & Description & Points \\
\hline $\begin{array}{l}\text { Cystic or almost } \\
\text { completely cystic }\end{array}$ & 0 & Anechoic & 0 & $\begin{array}{l}\text { Wider than } \\
\text { tall }\end{array}$ & 0 & Smooth & 0 & $\begin{array}{c}\text { None or large } \\
\text { comet-tail artifacts }\end{array}$ & 0 \\
\hline Spongiform & 0 & $\begin{array}{l}\text { Hyperechoic or } \\
\text { isoechoic }\end{array}$ & 1 & $\begin{array}{l}\text { Taller than } \\
\text { wide }\end{array}$ & 3 & Ill-defined & 0 & Macrocalcifications & 1 \\
\hline $\begin{array}{l}\text { Mixed cystic and } \\
\text { solid }\end{array}$ & 1 & Hypoechoic & 2 & & & $\begin{array}{l}\text { Lobulated or } \\
\text { irregular }\end{array}$ & 2 & $\begin{array}{l}\text { Peripheral (rim) } \\
\text { calcifications }\end{array}$ & 2 \\
\hline $\begin{array}{l}\text { Solid or almost } \\
\text { completely solid }\end{array}$ & 2 & Very hypoechoic & 3 & & & $\begin{array}{c}\text { Extrathyroidal } \\
\text { extension }\end{array}$ & 3 & $\begin{array}{l}\text { Punctate echogenic } \\
\text { foci }\end{array}$ & 3 \\
\hline
\end{tabular}


TABLE 2

Categories and Risk of Malignancy of Thyroid Nodules According to TI-RADS* Vs. EU-TIRADS ${ }^{\dagger}$

\begin{tabular}{|c|c|c|c|c|c|c|c|}
\hline \multicolumn{2}{|c|}{ Category } & \multicolumn{2}{|r|}{ Features } & \multicolumn{2}{|c|}{ Risk of malignancy } & \multicolumn{2}{|c|}{ Indication for FNAB } \\
\hline ACR & $\begin{array}{l}\text { EU- } \\
\text { TIRADS }\end{array}$ & ACR & EU-TIRADS & ACR & EU-TIRADS & ACR & EU-TIRADS \\
\hline TR1 & 1 & 0 points & No nodules & $<2 \%$ & Not applicable & No & Not applicable \\
\hline TR2 & 2 & 2 points & Anechoic or entirely spongiform & $<2 \%$ & $0 \%$ & No & $\begin{array}{l}\text { No, unless } \\
\text { compressive }\end{array}$ \\
\hline TR3 & 3 & 3 points & $\begin{array}{l}\text { Oval shape, smooth margins, and } \\
\text { entirely isoechoic or hyperechoic }\end{array}$ & $5 \%$ & $2 \%-4 \%$ & $\begin{array}{l}\text { Yes if } \geq 25 \mathrm{~mm} \\
\text { surveillance if } \\
\quad \leq 15 \mathrm{~mm}\end{array}$ & Yes if $>20 \mathrm{~mm}$ \\
\hline TR4 & 4 & $\begin{array}{c}4-6 \\
\text { points }\end{array}$ & Mildly hypoechoic & $5 \%-20 \%$ & $6 \%-17 \%$ & $\begin{array}{l}\text { Yes if } \geq 15 \mathrm{~mm} \\
\text { surveillance if } \\
\quad \geq 10 \mathrm{~mm}\end{array}$ & Yes if $>15 \mathrm{~mm}$ \\
\hline TR5 & 5 & $\begin{array}{l}\geq 7 \\
\text { points }\end{array}$ & $\begin{array}{l}\text { Nonoval/round shape (taller than wide), } \\
\text { irregular margins, microcalcifications, } \\
\text { or markedly hypoechoic }\end{array}$ & $>20 \%$ & $26 \%-87 \%$ & $\begin{array}{l}\text { Yes if } \geq 10 \mathrm{~mm} \\
\text { surveillance if } \\
\quad \geq 5 \mathrm{~mm}\end{array}$ & $\begin{array}{l}\text { Yes if }>10 \mathrm{~mm} \text {; } \\
\text { active surveillance } \\
\text { if }<10 \mathrm{~mm}\end{array}$ \\
\hline
\end{tabular}

${ }^{*}$ TR1 = benign; TR2 = not suggestive; TR3 = mildly suggestive; TR4 = moderately suggestive; TR5 = highly suspicious.

${ }^{\dagger} 1=$ normal (no nodules); 2 = benign; $3=$ low risk; $4=$ intermediate risk; 5 = high risk.

can be classified as benign by ultrasound criteria alone, and nodules with low-risk features have a false-negative risk of only $0.3 \%$ (12). It is still debated which TI-RADS version provides a better outcome $(16,17)$. Ultrasound guidance is crucial to localize sites for fineneedle aspiration biopsy (FNAB) (18) and minimally invasive therapeutic procedures (19).

\section{FNAB of Thyroid Nodules}

The prevalence of thyroid cancer in patients referred for goiter evaluation is $4 \%-18 \%(20)$. FNAB should be performed in suggestive nodules with high-risk ultrasound features, especially if combined with the scintigraphic features described further below. Table 3 summarizes the main features of the 2 most widely used systems for classifying the cytology findings according to the risk of malignancy, the Bethesda system and the British Thyroid Association system. Approximately $20 \%$ of FNABs of thyroid nodules have indeterminate cytology (Bethesda score III, or British Thyroid Association score Thy3a-f), with a rate of malignancy of $10 \%-30 \%$ (21). Molecular testing for gene mutations (e.g., BRAF, RAS, RET/
PTC, and PPAR $\gamma$ ) enhances the accuracy of FNAB in nodules with indeterminate cytology $(22,23)$.

\section{Diagnostic and Therapeutic Radionuclide Procedures}

Thyroid Scintigraphy with ${ }^{123}$ I-Iodide or ${ }^{99 m}$ Tc-Pertechnetate. Thyroid scintigraphy provides a map of functioning thyroid parenchyma (Fig. 2), including hypofunctioning nodules (cold areas on the scan) or autonomously functioning nodules (hot areas on the scan, with variable uptake in the extranodular thyroid parenchyma, up to complete suppression). Combined with ultrasonography, thyroid scintigraphy can determine which thyroid nodules should be characterized with FNAB (24). Nodules that appear as warm or hot on thyroid scintigraphy are rarely malignant (25); therefore, FNAB of such lesions is not indicated (Fig. 3).

In areas with sufficient dietary iodine intake, thyroid scintigraphy is not necessary in patients with diffuse, nodular, or multinodular goiter when serum TSH is normal, because all such nodules usually appear as cold areas on the scan and should be evaluated with FNAB if

TABLE 3

Prognostic Stratification of Cytology Findings After FNAB of Thyroid Nodules According to Bethesda Reporting System Vs. British Thyroid Association (BTA) Reporting System

\begin{tabular}{|c|c|c|c|c|c|}
\hline \multicolumn{2}{|c|}{ Category } & \multicolumn{2}{|l|}{ Features } & \multicolumn{2}{|c|}{ Risk of malignancy } \\
\hline Bethesda & BTA & Bethesda & BTA & Bethesda & BTA \\
\hline 1 & Thy 1 & Nondiagnostic & Nondiagnostic & $1 \%-4 \%$ & $4.5 \%-8.5 \%$ \\
\hline II & Thy2 & Benign & Nonneoplastic & $0 \%-3 \%$ & $0 \%-3 \%$ \\
\hline III & Thy3a & $\begin{array}{l}\text { Atypia of undetermined significance/follicular } \\
\text { lesion of undetermined significance }\end{array}$ & Nondiagnostic atypia & $5 \%-15 \%$ & $\sim 10 \%$ \\
\hline IV & Thy3f & $\begin{array}{c}\text { Follicular neoplasm/suspected follicular } \\
\text { neoplasm }\end{array}$ & $\begin{array}{l}\text { Suspected follicular } \\
\text { neoplasm }\end{array}$ & $15 \%-30 \%$ & $35 \%-40 \%$ \\
\hline V & Thy4 & Suspected malignancy & Suspected malignancy & $60 \%-75 \%$ & $68 \%-70 \%$ \\
\hline VI & Thy5 & Malignant & Diagnostic of malignancy & $97 \%-99 \%$ & $98 \%-99 \%$ \\
\hline
\end{tabular}




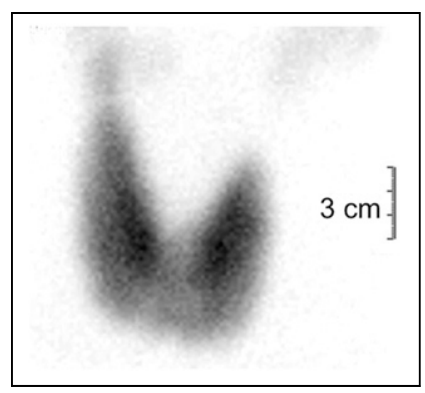

FIGURE 2. Thyroid scintigraphy (anterior view) acquired 15 min after intravenous injection of ${ }^{99 \mathrm{~m}} \mathrm{Tc}$-pertechnetate in patient with diffuse, nonnodular goiter and normal thyroid function, showing global hyperplasia of thyroid with homogeneous tracer distribution within gland. Right lobe is larger than left, with longitudinal axis measuring about $70 \mathrm{~mm}$.

${ }^{18}$ F-FDG PET/CT Incidentalomas - when an roid (usually in patients with nonthyroid cans not related to the thytracer uptake in the thyroid gland-are seen in $1 \%-2 \%$ of all ${ }^{18} \mathrm{~F}$ FDG scans. Two patterns of ${ }^{18} \mathrm{~F}-\mathrm{FDG}$ uptake have been observed, diffuse and focal (Fig. 4). Diffuse ${ }^{18}$ F-FDG uptake in the thyroid gland is usually associated with autoimmune thyroiditis and has little or no clinical relevance $(30-32)$. Focal ${ }^{18}$ F-FDG uptake in the thyroid gland can be found in nodular goiter, and about $35 \%$ of these incidentalomas are thyroid cancer (33). Therefore, these cases should be further investigated for unequivocal characterization (34). The occurrence of thyroid incidentalomas during a PET/CT scan is not unique to ${ }^{18} \mathrm{~F}-\mathrm{FDG}$, as they can be observed also with other PET tumor imaging agents, for example, ${ }^{18} \mathrm{~F}$-fluorocholine, ${ }^{68} \mathrm{Ga}$-DOTATOC, and ${ }^{68} \mathrm{Ga}$-prostate-specific membrane antigen ligand (Fig. 5) (35-37).

${ }^{18}$ F-FDG-avid thyroid nodules that cannot be classified with FNAB cytology are more likely to be malignant than a nodule without enhanced ${ }^{18}$ F-FDG uptake (Fig. 6); whereas a similar thyroid nodule without increased ${ }^{18} \mathrm{~F}$-FDG uptake is highly unlikely to be malignant (38-40). Although any focal ${ }^{18} \mathrm{~F}-\mathrm{FDG}$ uptake above the normal thyroid background is interpreted as positive and a high $\mathrm{SUV}_{\text {max }}$ increases the risk of malignancy $(39,41)$, no specific SUV$\max$ threshold has been identified to reliably discriminate malignant from benign thyroid nodules.

\section{Therapy of Nodular Goiter}

Surgery. Compressive symptoms are a major indication for surgery, as stated by the American Thyroid Association and by the German Society for General and Visceral Surgery (42).

Radioiodine Therapy for Reduction of Goiter Volume. Patients who have either diffuse or nodular goiter with mechanical symptoms and cannot undergo surgery because of comorbidities (43) can be treated with radioiodine. A practical approach to determine the activity to be administered is based on the assumption of a target activity of $3.7 \mathrm{MBq}(100 \mu \mathrm{Ci})$ of radioiodine per gram of functioning thyroid tissue $24 \mathrm{~h}$ after administration. The initial estimate (i.e., $3.7 \mathrm{MBq} \times$ volume of functioning thyroid tissue as assessed by thyroid scintigraphy) is corrected by the $24-\mathrm{h}$ radioiodine uptake value. More personalized dosimetry-based approaches to determine the activity of radioiodine for therapy (44) were discussed in part 1 of this continuing education article (1). Whereas in Graves' disease the target absorbed dose necessary to ablate hyperfunctioning thyroid tissue is between 200 and $400 \mathrm{~Gy}$, data derived from external-beam radiation therapy for cancers of the head and neck suggest that an absorbed dose of between 100 and 150 Gy is sufficient for ablation of normal thyroid parenchyma $(45,46)$.

This treatment causes an average $30 \%-40 \%$ volume reduction within $1 \mathrm{y}$ after treatment, with a further reduction of up to $50 \%-60 \%$ of the initial thyroid volume or mass in the following year (43). To increase radioiodine uptake in multinodular glands, an off-label use of recombinant human TSH, administered intramuscularly as a single $0.3-\mathrm{mg}$ dose $24 \mathrm{~h}$ before radioiodine therapy, has been suggested (47-51). An advantage of pretreatment with recombinant human TSH is that the activity of administered radioiodine is reduced by about half the activity that should be administered without recombinant human TSH before treatment, with a consequent reduction in overall radiation dosimetry $(52,53)$.

Besides the usual contraindication in pregnant or lactating women, some conditions must be fulfilled before submitting patients to this treatment. Evaluation for malignancy (ultrasonography, thyroid scintigraphy, and FNAB if necessary) must be performed before radioiodine therapy. The total thyroid volume or mass must be evaluated for bulky goiters extending to the upper mediastinum (which may require evaluation by MRI or by $\mathrm{CT}$ without contrast agent). The active thyroid volume or mass should be evaluated by thyroid scintigraphy, considering that cystic lesions and other low-uptake areas are not expected to respond to radioiodine therapy.

Since most patients treated with radioiodine develop hypothyroidism within 2-3 y after therapy, all patients receiving radioiodine therapy should be followed with semiannual serum TSH assays $(42,54)$.

\section{Medical Therapy of Nodular Goiter}

Once their benign nature has been established, goiters with small nodules usually do not require treatment and can safely be monitored with regular follow-up. Since iodine deficiency has a key role in

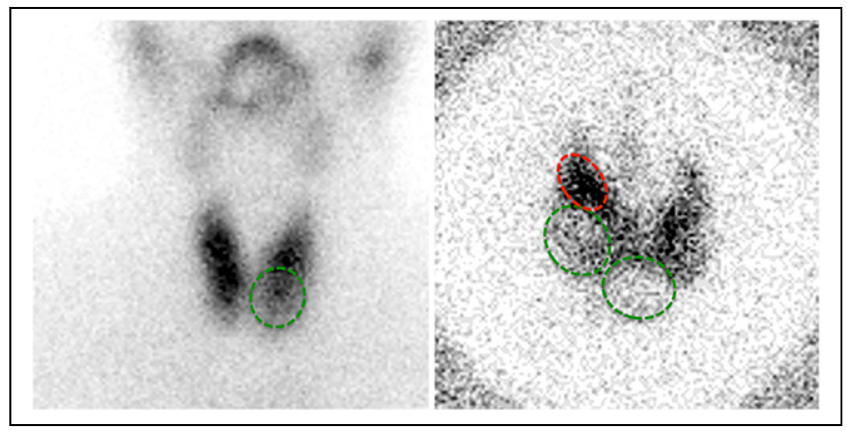

FIGURE 3. Thyroid scintigraphy in 2 patients with nodular goiter (anterior view). (Left) ${ }^{99 m}$ Tc-pertechnetate scan acquired 15 min after intravenous injection, showing moderately enlarged gland with reduced tracer uptake in lower half of left lobe, corresponding to palpable nodule (outlined in green); if suggestive ultrasound features are seen for this nodule, patient should be referred for FNAB. (Right) scan acquired with pinhole collimator $24 \mathrm{~h}$ after oral administration of $1.85 \mathrm{MBq}$ of ${ }^{131}$ I-iodide to see whether patient is candidate for radioiodine therapy of multinodular goiter with autonomously functioning nodules; only nodule at apex of right lobe (outlined in red) shows increased tracer uptake, whereas nodules at base of right lobe and at isthmus (outlined in green) do not concentrate radioiodine (cold nodules); FNAB was performed because of intermediate-risk EU-TIRADS score and showed both nodules to be benign. 
thyroid enlargement, iodine supplementation may reduce goiter size $(55,56)$.

Historically, TSH-suppressive therapy with L-thyroxine was used with the aim of reducing stimulation of thyroid parenchyma and nodules. Although this approach was widely embraced in the past (56-59), the long-term outcomes of this approach are still controversial (59). Current American Thyroid Association guidelines do not recommend the routine use of L-thyroxine for the treatment of benign thyroid nodules (14), although it may remain a feasible option for young patients in cases of mild iodine deficiency $(59,60)$.

\section{Minimally Invasive Treatments for Nodular Goiter}

Tissue ablation techniques have been developed to induce necrosis or apoptosis of specific thyroid nodules. Recent minimally invasive techniques induce thermal ablation with different forms of energy such as microwaves, radiofrequency, high-intensity focused ultrasound, or laser energy (14).

\section{HYPOTHYROIDISM}

\section{Epidemiology and Clinical Presentation}

Hypothyroidism is a systemic condition caused by transient or permanent thyroid failure (primary hypothyroidism), deficiency of thyrotropin secretion (TSH) (secondary, or central hypothyroidism), or resistance of peripheral target tissues (Supplemental File 3).

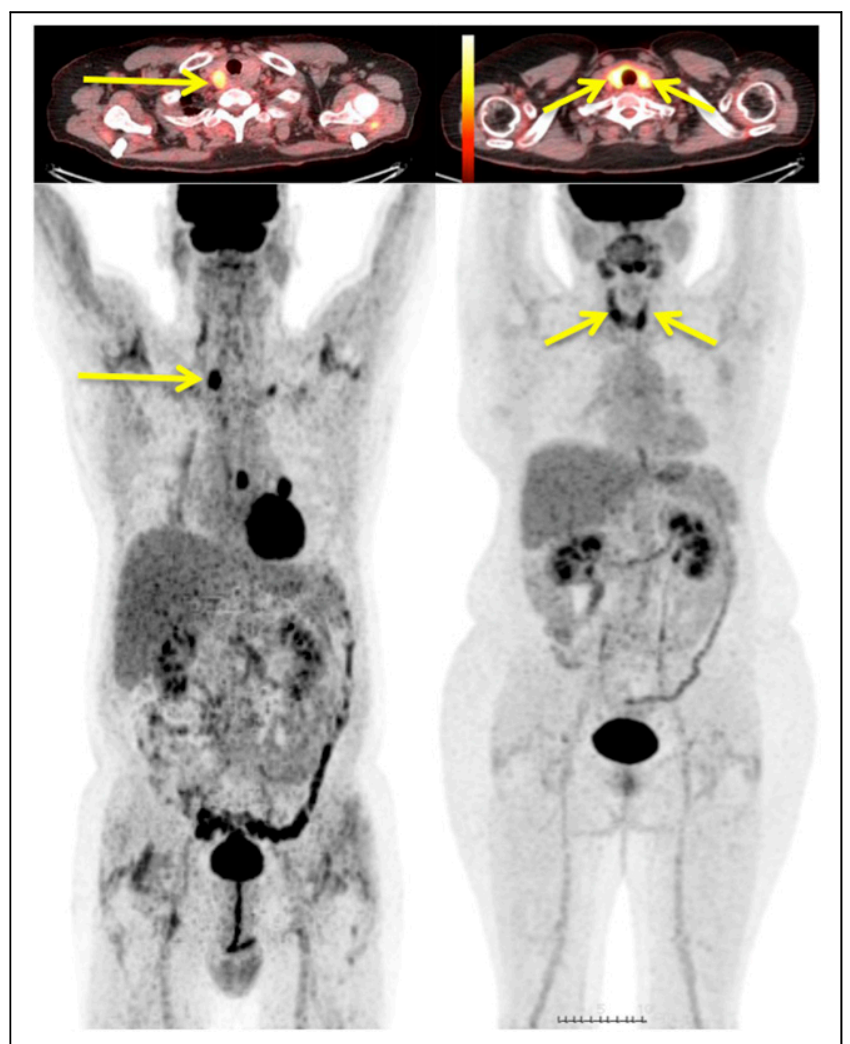

FIGURE 4. Thyroid incidentalomas observed in 2 patients undergoing ${ }^{18} \mathrm{~F}-$ FDG PET/CT for thyroid-unrelated oncologic conditions (top: axial PET/CT; bottom: whole-body maximum-intensity-projection image). Arrows indicate unexpected findings of focally increased tracer uptake (left) and diffuse tracer uptake (right). Although diffusely enhanced tracer uptake is generally associated with thyroiditis, any focal increase in tracer uptake must be further evaluated with ultrasound and possibly FNAB, because of relatively high rate of thyroid malignancy.
The spectrum of hypothyroidism ranges from severe overt hypothyroidism (myxedema) to milder forms - that is, subclinical hypothyroidism. Primary hypothyroidism accounts for $95 \%-99 \%$ of thyroid failure and usually has an autoimmune etiology. Deficiency of pituitary or hypothalamic function (secondary or tertiary hypothyroidism) and peripheral resistance to thyroid hormones, or their inactivation due to autoantibodies, are rare.

The prevalence of hypothyroidism in the United States (defined as TSH levels $>4.5 \mathrm{mIU} / \mathrm{L}$ ) is $3.7 \%$ of the general population (61). In Europe it is $0.65 \%(95 \% \mathrm{CI}, 0.38 \%-0.99 \%)$ for overt and $4.11 \%$ (95\% CI, 3.05\%-5.31\%) for subclinical hypothyroidism (62).

Congenital Hypothyroidism. Congenital hypothyroidism is the most frequent congenital endocrine disorder (1:2,200-2,500 live births). Delayed diagnosis leads to growth retardation and severe neurologic and psychiatric impairment.

Children and Adolescent Hypothyroidism. Hypothyroidism in children and adolescents is characterized by retarded growth and short stature, variable but usually declining school performance, and signs or symptoms similar to those occurring in adults. In addition to the history and physical examination, laboratory evaluation should include TSH, free T4, and free T3. In the presence of abnormal findings, the patient should be referred to a pediatric endocrinologist.

Hypothyroidism in Adults. Thyroid hormone deficiency reduces function in almost every organ system depending on the degree of hypothyroidism (Table 4).

Hypothyroidism in the Elderly. The most frequent signs or symptoms in the elderly are fatigue, muscle weakness, cold intolerance, dry skin, hair loss, constipation, poor appetite, depression or mental deterioration, hearing loss, cardiomegaly, and congestive heart failure.

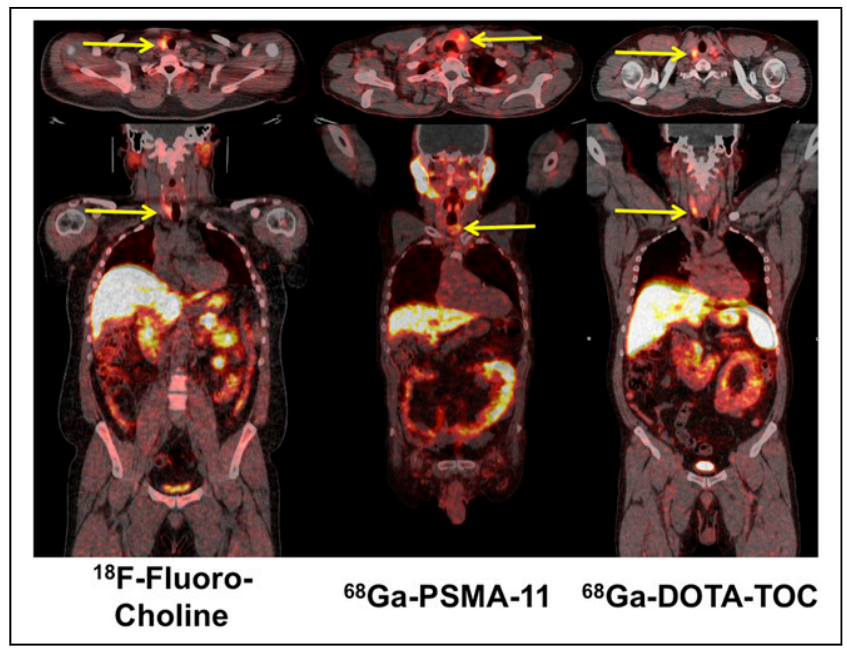

FIGURE 5. Thyroid incidentalomas (arrows) observed in 3 patients evaluated with PET tracers other than ${ }^{18} \mathrm{~F}-\mathrm{FDG}$ for oncologic conditions (top: axial PET/CT; bottom: coronal PET/CT). (Left) Patient with biochemical recurrence of prostate cancer, who had previously undergone left hemithyroidectomy because of nodular goiter. Histology showed chronic autoimmune thyroiditis. Diffusely enhanced ${ }^{18} \mathrm{~F}$-fluorocholine uptake in residual right thyroid lobe corresponds to autoimmune thyroiditis. (Center) Patient with focally increased ${ }^{68}$ Ga-prostate-specific membrane antigen 11 uptake within multinodular goiter prevalent in left lobe. (Right) Patient with focally increased ${ }^{68} \mathrm{Ga}$-DOTATOC uptake in right thyroid lobe. (Courtesy of Paola A. Erba and Roberta Zanca, Regional Center of Nuclear Medicine, University of Pisa, Pisa, Italy.) 


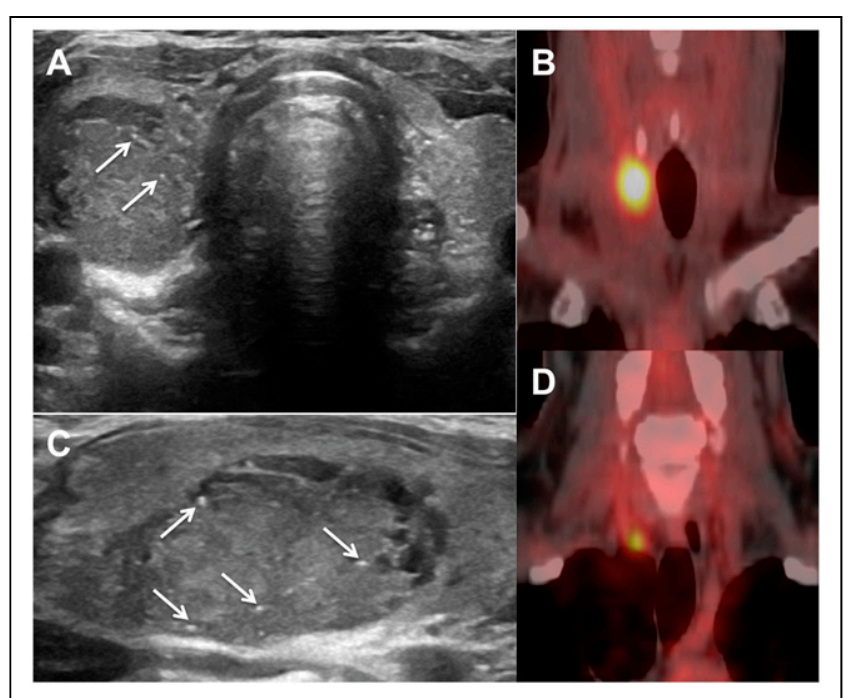

FIGURE 6. Evaluation of 30-y-old woman with family history of familial papillary thyroid carcinoma. Axial (A) and longitudinal (C) ultrasonography shows 25-mm mixed isoechoic-hypoechoic solid nodule of right lobe, with microcalcifications (arrows). Serum calcitonin was undetectable, and TSH was 2.7 $\mu \mathrm{lU} / \mathrm{mL}$; FNAB showed high-risk undetermined lesion (British Thyroid Association grade Thy3f). (B) Coronal ${ }^{18} \mathrm{~F}-\mathrm{FDG}$ PET/CT showed intense focal uptake $\left(S_{\text {max }}, 12\right)$ in thyroid nodule of right lobe. (D) Another coronal image showed additional focus of increased ${ }^{18} \mathrm{~F}$-FDG uptake in deeper plane, corresponding to small lymph node of central compartment not detected at ultrasonography. Patient underwent thyroidectomy and lymph node dissection of central compartment, which revealed BRAF-mutated papillary thyroid carcinoma with multiple lymph node metastases. (Courtesy of Arnoldo Piccardo, Nuclear Medicine Department, "Galliera” Hospital, Genoa, Italy.)

Drug-Induced Hypothyroidism. The large amount of iodine released from amiodarone (an iodine-rich drug used for treating tachyarrhythmias) may fail to escape the Wolff-Chaikoff effect (described in the next section) and thus cause iodine-induced hypothyroidism, especially in patients with preexisting autoimmune thyroiditis $(63,64)$. Lithium therapy may cause hypothyroidism by blocking both release and synthesis of thyroid hormones (65). Interferon may precipitate hypothyroidism, either by aggravating preexisting autoimmune thyroiditis or by a direct cytotoxic effect on thyroid follicular cells (66). Tyrosine kinase inhibitors may induce hypothyroidism by mechanisms not fully understood (67).

\section{Pathophysiology}

The most frequent cause of hypothyroidism in adults is autoimmune thyroiditis (Ord-Hashimoto disease). It most probably results from a combination of a predisposing genetic background with exogenous and endogenous factors (68). Infiltration of thyroid tissue by amyloidosis, hemochromatosis, sarcoidosis, cystinosis, scleroderma, or leukemia may also cause hypothyroidism and goiter.

Hypothyroidism may result from either severe iodine deficiency or iodine excess. In severe iodine deficiency, large goiters and variable degrees of hypothyroidism may be observed at any age. Excess iodine intake $(>1-2 \mathrm{mg} / \mathrm{d})$ acutely inhibits iodine organification and thyroid hormone synthesis (Wolff-Chaikoff effect) as well as thyroid hormone release. In most euthyroid subjects, iodine excess does not cause hypothyroidism, because there is an adaptive mechanism (escape, usually at $\sim 10 \mathrm{~d}$ after iodine loading); nevertheless, patients with preexisting thyroid abnormalities may fail to escape the Wolff-Chaikoff effect and thus develop hypothyroidism.
Iatrogenic hypothyroidism can be observed after treatment of hyperthyroidism with antithyroid drugs or radioiodine, as well as after total thyroidectomy or external-beam radiation therapy of the head and neck region.

\section{Lab Tests}

TSH. Primary hypothyroidism is characterized by increased TSH and decreased free T4; in subclinical hypothyroidism TSH is increased (generally between 5 and $10 \mathrm{mIU} / \mathrm{L}$ ) and free T4 is normal. In central hypothyroidism, low free T4 is associated with low-to-inappropriately normal TSH.

Antibodies. Thyroid peroxidase antibodies and thyroglobulin antibodies are positive in most patients with autoimmune thyroiditis.

Lipids. In both overt and subclinical hypothyroidism, the lipid profile shows increased low-density lipoprotein cholesterol levels, with increased or normal high-density lipoprotein levels. Triglyceride levels are normal or slightly elevated.

\section{Ultrasound Imaging}

In hypothyroidism, the thyroid volume can be normal, increased (goiter), or reduced (atrophic form of chronic autoimmune thyroiditis, hypoplasia, or hemiagenesis) (Supplemental File 4). Inhomogeneous hypoechogenicity is typical of chronic autoimmune thyroiditis. Ultrasonography can also identify ectopic thyroid tissue in congenital hypothyroidism.

\section{Radionuclide Techniques in Hypothyroidism}

Nuclear medicine currently has a limited role in hypothyroidism, since the diagnosis is based on signs or symptoms and on thyroid hormonal profile (TSH, free T3, free T4). The only current application of radionuclide imaging in hypothyroidism concerns congenital hypothyroidism (69). Thyroid scintigraphy with either ${ }^{99 \mathrm{~m}} \mathrm{Tc}$-pertechnetate or preferably ${ }^{123}$ I-iodide constitutes the best standard for ascertaining thyroid agenesis or locating ectopic thyroid tissue in the mediastinum or at the base of the tongue, especially in newborns/children.

When the thyroid gland is in its normal location in a patient with congenital hypothyroidism, the cause of hypothyroidism can be genetic mutation, over 25 of which have been described $(70,71)$. The perchlorate discharge test explores defects in the intrathyroidal organification process of iodide as a cause of congenital hypothyroidism. Once iodide is trapped in the thyroid gland after active transport mediated by sodium/iodide symporter, iodine binds to thyroglobulin, therefore no longer requiring active transport for intracellular retention. Perchlorate ions inhibit sodium/iodide symporter-mediated iodide transport and cause loss of iodide not bound to thyroid hormones. Evaluating the release of radioiodine caused by perchlorate allows evaluation of nonorganified intrathyroidal iodide and thus assessment of an iodide-binding defect (69).

\section{Thyroid Replacement Therapy in Hypothyroidism}

Approximately $85 \mu \mathrm{g}$ of L-thyroxine are secreted by the thyroid gland daily. Of the total daily $\mathrm{T} 3$ production (about $33 \mu \mathrm{g}$ in adult healthy humans), approximately $80 \%$ arises from peripheral conversion from T4, and only about $20 \%$ derives from direct thyroidal secretion. Synthetic L-thyroxine is recommended as the preparation of choice to treat hypothyroidism, because of its efficacy, favorable side-effect profile, ease of administration, good intestinal absorption, long serum half-life, and low cost. L-thyroxine is converted in vivo into its active metabolite T3. 
TABLE 4

Major Pathophysiologic and Clinical Changes in Moderate or Severe Hypothyroidism

\begin{tabular}{|c|c|}
\hline Target tissue or organ & Deficient thyroid hormone \\
\hline All tissues and organs & $\begin{array}{l}\text { Decreased basal metabolic rate and thermogenesis (increased sensitivity to cold), weight gain, } \\
\text { fatigue }\end{array}$ \\
\hline $\begin{array}{l}\text { Cardiovascular and renal } \\
\text { function }\end{array}$ & $\begin{array}{l}\text { Bradycardia, reduced contractility, dyspnea on exertion, reduced exercise tolerance, reduced } \\
\text { glomerular filtration rate }\end{array}$ \\
\hline Nervous system & $\begin{array}{l}\text { Impaired cognitive and memory functions, somnolence, vertigo, headache, numbness or tingling in } \\
\text { extremities, decreased peripheral reflexes }\end{array}$ \\
\hline Gastrointestinal tract & Constipation or obstipation, increased gallstone formation \\
\hline Skin and skin annexes & Dry skin; hair thinning or loss; edema of hands, face, eyelids; pallor \\
\hline Musculoskeletal & Muscle weakness; muscle aches, tenderness, and stiffness; joint pain; carpal tunnel syndrome \\
\hline Reproductive apparatus & Oligodysmenorrhea, infertility (in women and men), miscarriages \\
\hline
\end{tabular}

Nevertheless, a subgroup of hypothyroid patients does not achieve good results with L-thyroxine therapy alone (72); in these patients, combination therapy with L-thyroxine and liothyronine (L-T3) might be considered $(73,74)$.

Hypothyroid patients with minimal endogenous thyroid function require L-thyroxine doses of $1.6-1.8 \mu \mathrm{g} / \mathrm{kg}$ of body weight (ideal body weight being a better predictor than actual body weight). Patients with L-thyroxine dose requirements much higher than expected should be evaluated for gastrointestinal disorders such as Helicobacter pylori-related gastritis, atrophic gastritis, celiac disease, lactose intolerance, and intestinal giardiasis. Serum TSH monitoring is advisable when starting medications such as phenobarbital, phenytoin, carbamazepine, rifampin, and sertraline.

Symptoms, such as cold intolerance or dry skin, lack sensitivity and specificity and therefore are not recommended for judging the adequacy of replacement in the absence of biochemical assessment.

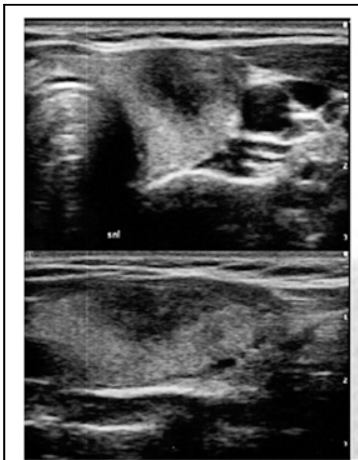

Baseline ultrasound

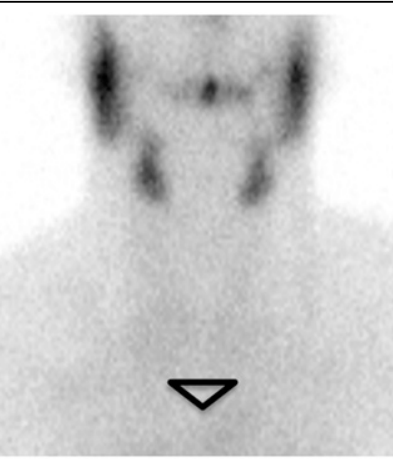

Baseline scintigraphy

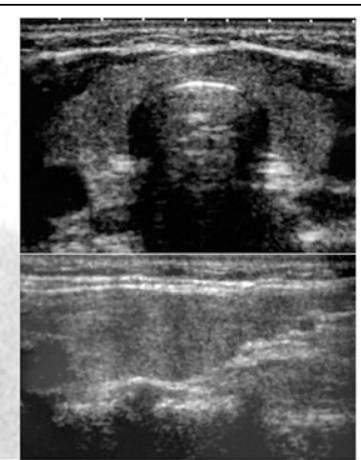

1 y follow-up ultrasound
FIGURE 7. Ultrasound and scintigraphy images of 46-y-old woman with subacute thyroiditis arising in preexisting chronic autoimmune thyroiditis. At presentation, patient had tender goiter and pain while swallowing but no fever. Leukocyte count and erythrocyte sedimentation rate were abnormally increased, but C-reactive protein level was normal. TSH level was $0.01 \mathrm{mlU} / \mathrm{L}$, with increased free T3 (almost 2-fold upper normal limit) and free T4 (1.5-fold upper normal limit). (Left) Axial (top) and longitudinal (bottom) ultrasound scans at baseline show markedly hypoechoic area in left thyroid lobe, with poorly defined margins. Anterior ${ }^{99 m}$ Tc-pertechnetate scintigraphy scan at presentation shows minimal tracer uptake in thyroid gland, with physiologic visualization of parotid and submandibular salivary glands; arrowhead indicates sternal notch. Axial (top) and longitudinal (bottom) ultrasonography scans obtained 1 y later show almost complete recovery of abnormalities observed on baseline ultrasound. Thyroidal hormonal profile was completely normal at this time.
About 6-8 wk after a change in L-thyroxine dosage, serum TSH should be checked.

\section{SUBACUTE THYROIDITIS}

Subacute thyroiditis is a self-limited inflammation of the thyroid Painless subacute thyroiditis may be overlooked or misdiag Pecially when occurring in the postpartum period, occasionally

Originally described in 1895 by Mygind as "thyroiditis was first depicted in 1904 by the Swiss surgeon Fritz de Querprocess causes disruption of thyroid follicles resulting stored T4 and T3 causing an initial thyrotoxic phase, often followed by transient or permanent hypothyroidism.

Epidemiology and Clinical Presentation

The incidence of subacute thyroiditis is $4.9 / 100,000$ people per year (78). Its prevalence is highest in middle-aged women (range of female-to-male ratio, 4:1-7:1). Subacute thyroiditis often occurs after an upper respiratory viral illness, thought to trigger the disease.

Anterior neck pain is the cardinal feature of de Quervain subacute thyroiditis. The inflammation can start in one lobe and then migrate to the contralateral lobe. Dysphagia is occasionally reported. The gland is firm and tender on palpation. In the early phases there can be signs of thyrotoxicosis (tachycardia, tremor, increased skin warmth), sometimes requiring the use of a $\beta$-blocker. The thyrotoxic phase may be followed by hypothyroidism, which is usually transient, although it can occasionally be permanent. In patients with hypothyroid symptoms, L-thyroxine replacement should be started, with frequent TSH monitoring 
to assess possible tapering or continuation of replacement therapy.

\section{Etiology and Pathophysiology}

Although subacute thyroiditis has been related to a viral infection (79), so far no infective agent has been clearly identified (80). The destructive events of subacute thyroiditis may trigger thyroid autoimmunity in subjects with a genetic background, occasionally resulting in chronic autoimmune thyroiditis with hypothyroidism $(81)$ or in Graves disease (82).

About $72 \%$ of patients with subacute thyroiditis present the HLABW35 antigen (83), and familial subacute thyroiditis can be associated with HLA-B35 (84), suggesting that the disease may be caused by a viral infection in genetically predisposed individuals. Therapies potentially affecting the immune system may be associated with subacute thyroiditis (85), as in patients with chronic hepatitis B or C treated with interferon or ribavirin (66).

\section{Lab Tests}

Laboratory exams show a moderate leukocytosis, elevated erythrocyte sedimentation rate, and elevated serum C-reactive protein levels. In the thyrotoxic phase, suppressed serum TSH is associated with normal or elevated free T3 and free T4. The thyrotoxic phase typically lasts 4-8 wk. Thyroglobulin levels are elevated because of the destruction of thyroid follicles.

\section{Ultrasound Imaging}

Thyroid ultrasound shows heterogeneous, diffuse, hypoechoic and confluent areas, with no increase in the vascularity on color Doppler imaging (86). These abnormalities often revert to a nearnormal pattern when the condition resolves (Fig. 7).

\section{Radionuclide Imaging}

Thyroid scintigraphy is characterized by very low or absent tracer uptake in the thyroid gland in the thyrotoxic phase, a pattern shared by other conditions of destructive thyroiditis (e.g., type 2 amiodarone-induced thyroid dysfunction). Depending on the phase of the illness, tracer uptake can be absent in the whole gland or in part of the gland. Even when subacute thyroiditis affects primarily one lobe of the thyroid, the scan may show a completely absence of tracer uptake in the whole gland (Fig. 7) because of suppressed TSH levels due to a thyrotoxic phase of the disease.

\section{Therapy of Subacute Thyroiditis}

Since subacute thyroiditis is self-limited, in most cases the thyroid gland spontaneously resumes normal thyroid hormone production. Treatment is directed toward relief of thyroid pain. High-dose nonsteroidal antiinflammatory drugs are usually the first-line treatment (75). If neck pain does not improve after a few days, or if the patient presents with severe neck pain, corticosteroids may be considered (80), which leads to improvement within $2 \mathrm{~d}$. After 5-7 d of highdose prednisone, the dose is tapered over the next 2-4 wk. As the dose is tapered, most patients have no recurrence of symptoms, but occasionally symptoms do recur and the dose must be increased again.

Thyroid hormone supplementation is generally not necessary for the transient hypothyroid phase of subacute thyroiditis, unless patients are symptomatic. However, permanent hypothyroidism develops in up to $15 \%$ of patients, even more than $1 \mathrm{y}$ after presentation (75).

\section{REFERENCES}

1. Mariani G, Tonacchera M, Grosso M, Orsolini F, Vitti P, Strauss HW. The role of nuclear medicine in the clinical management of benign thyroid disorders, part 1: hyperthyroidism. J Nucl Med. 2021;62:304-312.

2. Hurley DL, Gharib H. Evaluation and management of multinodular goiter. Otolaryngol Clin North Am. 1996;29:527-540.

3. Knudsen N, Bulow I, Jorgensen T, Laurberg P, Ovesen L, Perrild H. Goitre prevalence and thyroid abnormalities at ultrasonography: a comparative epidemiological study in two regions with slightly different iodine status. Clin Endocrinol (Oxf). 2000;53:479-485.

4. Aghini-Lombardi F, Antonangeli L, Martino E. The spectrum of thyroid disorders in an iodine-deficient community: the Pescopagano survey. J Clin Endocrinol Metab. 1999;84:561-566.

5. Vanderpump MP, Tunbridge WM, French JM. The incidence of thyroid disorders in the community: a twenty-year follow-up of the Whickham survey. Clin Endocrinol (Oxf). 1995;43:55-68.

6. Brix TH, Kyvik KO, Hegedüs L. Major role of genes in the etiology of simple goiter in females: a population-based twin study. J Clin Endocrinol Metab. 1999;84:30713075 .

7. Carlé A, Krejbjerg A, Laurberg P. Epidemiology of nodular goitre: influence of iodine intake. Best Pract Res Clin Endocrinol Metab. 2014;28:465-479.

8. Fiore E, Tonacchera M, Vitti P. Influence of iodization programmes on the epidemiology of nodular goitre. Best Pract Res Clin Endocrinol Metab. 2014;28: $577-588$.

9. Hegedüs L, Brix TH, Paschke R. Etiology of simple goiter. Thyroid. 2009;19:209211.

10. Knudsen N, Brix TH. Genetic and non-iodine-related factors in the aetiology of nodular goitre. Best Pract Res Clin Endocrinol Metab. 2014;28:495-506.

11. Christensen SB, Ericsson UB, Janzon L, Tibblin S, Melander A. Influence of cigarette smoking on goiter formation, thyroglobulin, and thyroid hormone levels in women. $J$ Clin Endocrinol Metab. 1984;58:615-618.

12. Russ G, Bonnema SJ, Erdogan MF, Durante C, Ngu R, Leenhardt L. European Thyroid Association guidelines for ultrasound malignancy risk stratification of thyroid nodules in adults: the EU-TIRADS. Eur Thyroid J. 2017;6:225-237.

13. Tessler FN, Middleton WD, Grant EG. ACR thyroid imaging, reporting and data system (TI-RADS): white paper of the ACR TI-RADS committee. J Am Coll Radiol. 2017; 14:587-595.

14. Haugen BR, Alexander EK, Bible KC. 2015 American Thyroid Association management guidelines for adult patients with thyroid nodules and differentiated thyroid cancer. The American Thyroid Association guidelines task force on thyroid nodules and differentiated thyroid cancer. Thyroid. 2016;26:1-133.

15. Gharib H, Papini E, Garber JR. American Association of Clinical Endocrinologists, American College of Endocrinology and Associazione Medici Endocrinologi medical guidelines for clinical practice for the diagnosis and management of thyroid nodules: 2016 update. Endocr Pract. 2016;22(suppl 1):622-639.

16. Magri F, Chytiris S, Croce L. Performance of the ACR TI-RADS and EU TI-RADS scoring systems in the diagnostic work-up of thyroid nodules in a real-life series using histology as reference standard. Eur J Endocrinol. 2020;183:521-528.

17. Tan L, Tarn YS, Tan S. Diagnostic accuracy and ability to reduce unnecessary FNAC: a comparison between four Thyroid Imaging Reporting Data System (TI-RADS) versions. Clin Imaging. 2020;65:133-137.

18. Carmeci C, Jeffrey RB, McDougall IR, Nowels KW, Weigel RJ. Ultrasound-guided fine-needle aspiration biopsy of thyroid masses. Thyroid. 1998;8:283-289.

19. Barile A, Quarchioni S, Bruno F. Interventional radiology of the thyroid gland: critical review and state of the art. Gland Surg. 2018;7:132-146.

20. Brito JP, Yarur AJ, Prokop LJ, McIver B, Murad MH, Montori VM. Prevalence of thyroid cancer in multinodular goiter versus single nodule: a systematic review and meta-analysis. Thyroid. 2013;23:449-455.

21. Ho AS, Sarti EE, Jain KS. Malignancy rate in thyroid nodules classified as Bethesda category III (AUS/FLUS). Thyroid. 2014;24:832-839.

22. Roth MY, Witt RL, Steward DL. Molecular testing for thyroid nodules: review and current state. Cancer. 2018;124:888-898.

23. Ferris RL, Baloch Z, Bernet V. American Thyroid Association statement on surgical application of molecular profiling for thyroid nodules: current impact on perioperative decision making. Thyroid. 2015;25:760-768.

24. Noto B, Eveslage M, Pixberg M. Prevalence of hyperfunctioning thyroid nodules among those in need of fine needle aspiration cytology according to ATA 2015, EU-TIRADS, and ACR-TIRADS. Eur J Nucl Med Mol Imaging. 2020;47:15181526.

25. Ashcraft MW, Van Herle AJ. Management of thyroid nodules. II: scanning techniques, thyroid suppressive therapy, and fine needle aspiration. Head Neck Surg. 1981;3:297-322. 
26. Haugen BR, Alexander EK, Bible KC. 2015 American Thyroid Association management guidelines for adult patients with thyroid nodules and differentiated thyroid cancer. The American Thyroid Association guidelines task force on thyroid nodules and differentiated thyroid cancer. Thyroid. 2016;26:1-133.

27. Giovanella L, Avram AM, Iakovu I. EANM practice guideline/SNMMI procedure standard for RAIU and thyroid scintigraphy. Eur J Nucl Med Mol Imaging. 2019; 46:2514-2525.

28. Chami R, Morenio-Reyes R, Corvilain B. TSH measurement is not an appropriate screening test for autonomous functioning thyroid nodules: a retrospective study of 368 patients. Eur J Endocrinol. 2014;170:593-599.

29. Treglia G, Trimboli P, Verburg FA, Luster M, Giovanella L. Prevalence of normal TSH value among patients with autonomously functioning thyroid nodule. Eur $J$ Clin Invest. 2015;45:739-744.

30. Agrawal K, Weaver J, Ngu R, Krishnamurthy Mohan H. Clinical significance of patterns of incidental thyroid uptake at ${ }^{18}$ F-FDG PET/CT. Clin Radiol. 2015;70:536543.

31. Małkowski B, Serafin Z, Glonek R, Suwała S, Łopatto R, Junik R. The role of ${ }^{18} \mathrm{~F}$ FDG PET/CT in the management of the autoimmune thyroid diseases. Front Endocrinol (Lausanne). 2019;10:208.

32. Albano D, Treglia G, Giovanella L, Giubbini R, Bertagna F. Detection of thyroiditis on PET/CT imaging: a systematic review. Hormones (Athens). 2020;19:341-349.

33. Pattison DA, Bozin M, Gorelik A. ${ }^{18}$ FDG-avid thyroid incidentalomas: the importance of contextual interpretation. J Nucl Med. 2018;59:749-755.

34. Trimboli P, Knappe L, Treglia G. FNA indication according to ACR-TIRADS, EU-TIRADS and K-TIRADS in thyroid incidentalomas at ${ }^{18} \mathrm{~F}-\mathrm{FDG}$ PET/CT. $J$ Endocrinol Invest. 2020;43:1607-1612.

35. Bertagna F, Albano D, Giovanella L. ${ }^{68}$ Ga-PSMA PET thyroid incidentalomas. Hormones (Athens). 2019;18:145-149.

36. Bertagna F. Albano D, Giovanella L, Giubbini R, Treglia G. F18-choline/C11-choline PET/CT thyroid incidentalomas. Endocrine. 2019;64:203-208.

37. Ciappuccini R, Edet-Sanson A, Saguet-Rysanek V, Gauthé M, Stéphane Bardet S. Thyroid incidentaloma on ${ }^{18} \mathrm{~F}$-fluorocholine PET/CT and ${ }^{68} \mathrm{Ga}-\mathrm{PSMA}$ PET/CT revealing a medullary thyroid carcinoma. Clin Nucl Med. 2019;44:663-665.

38. Vriens D, Adang EM, Netea-Maier RT. Cost effectiveness of FDG-PET/CT for cytologically indeterminate thyroid nodules: a decision analytic approach. JClin Endocrinol Metab. 2014;99:3263-3274.

39. Castellana M, Trimboli P, Piccardo A, Giovanella L, Treglia G. Performance of ${ }^{18}$ FFDG PET/CT in selecting thyroid nodules with indeterminate fine-needle aspiration cytology for surgery: a systematic review and a meta-analysis. J Clin Med. 2019;8: 1333.

40. Piccardo A, Puntoni M, Dezzana M. Indeterminate thyroid nodules: the role of ${ }^{18} \mathrm{~F}$ FDG PET/CT in the "era" of ultrasonography risk stratification systems and new thyroid cytology classifications. Endocrine. 2020;69:553-561.

41. Sager S, Vatankulu B, Erdem Sahin O. Clinical significance of standardized uptake values in thyroid incidentaloma discovered by F-18 fluorodeoxyglucose positron emission tomography/computed tomography. J Cancer Res Ther. 2018;14:989-993.

42. Bartsch DK, Luster M, Buhr HJ. Indications for the surgical management of benign goiter in adults. Dtsch Arztebl Int. 2018;115:1-7.

43. Bonnema SJ, Hegedüs L. A 30-year perspective on radioiodine therapy of benign nontoxic multinodular goiter. Curr Opin Endocrinol Diabetes Obes. 2009;16: 379-384.

44. Hammes J, van Heek L, Hohberg M. Impact of different approaches to calculation of treatment activities on achieved doses in radioiodine therapy of benign thyroid diseases. EJNMMI Phys. 2018;5:32.

45. Boomsma MJ, Bijl HP, Langendijk JA. Radiation-induced hypothyroidism in head and neck cancer patients: a systematic review. Radiother Oncol. 2011; 99:1-5.

46. Xu Y, Shao Z, Tang T. A dosimetric study on radiation-induced hypothyroidism following intensity-modulated radiotherapy in patients with nasopharyngeal carcinoma. Oncol Lett. 2018;16:6126-6132.

47. Bonnema SJ, Nielsen VE, Boel-Jørgensen H. Improvement of goiter volume reduction after $0.3 \mathrm{mg}$ recombinant human thyrotropin-stimulated radioiodine therapy in patients with a very large goiter: a double-blinded, randomized trial. J Clin Endocrinol Metab. 2007;92:3424-3428.

48. Ceccarelli C, Antonangeli L, Brozzi F. Radioiodine ${ }^{131}$ I treatment for large nodular goiter: recombinant human thyrotropin allows the reduction of radioiodine ${ }^{131}$ I activity to be administered in patients with low uptake. Thyroid. 2011;21: 759-764.

49. Bonnema SJ, Nielsen VE, Boel-Jørgensen H. Recombinant human thyrotropinstimulated radioiodine therapy of large nodular goiters facilitates tracheal decompression and improves inspiration. J Clin Endocrinol Metab. 2008;93: 3981-3984.
50. Lee Y-Y, Tam K-W, Lin Y-M. Recombinant human thyrotropin before ${ }^{131}$ I therapy in patients with nodular goitre: a meta-analysis of randomized controlled trials. Clin Endocrinol (Oxf). 2015;83:702-710.

51. Xu C, Wang P, Huikai Miao H. Recombinant human thyrotropin-stimulated radioiodine therapy in patients with multinodular goiters: a meta-analysis of randomized controlled trials. Horm Metab Res. 2020;52:841-849.

52. Nieuwlaat W-A, Hermus AR, Ross HA. Dosimetry of radioiodine therapy in patients with nodular goiter after pretreatment with a single, low dose of recombinant human thyroid-stimulating hormone. J Nucl Med. 2004;45:626-633.

53. Fast $\mathrm{S}$, Hegedüs L, Grupe P. Recombinant human thyrotropin-stimulated radioiodine therapy of nodular goiter allows major reduction of the radiation burden with retained efficacy. J Clin Endocrinol Metab. 2010;95:3719-3725.

54. Bonnema SJ, Hegedüs L. Radioiodine therapy in benign thyroid diseases: effects, side effects, and factors affecting therapeutic outcome. Endocr Rev. 2012;33: 920-980.

55. Hintze G, Kobberling J. Treatment of iodine deficiency goiter with iodine, levothyroxine or a combination of both. Thyroidology. 1992;4:37-40.

56. Diehl LA, Garcia V, Bonnema SJ. Management of the nontoxic multinodular goiter in Latin America: comparison with North America and Europe, an electronic survey. $J$ Clin Endocrinol Metab. 2005;90:117-123.

57. Gharib H, James EM, Charboneau JW. Suppressive therapy with levothyroxine for solitary thyroid nodules: a double-blind controlled clinical study. $N$ Engl J Med. 1987;317:70-75.

58. Papini E, Petrucci L, Guglielmi R. Long-term changes in nodular goiter: a 5-year prospective randomized trial of levothyroxine suppressive therapy for benign cold thyroid nodules. J Clin Endocrinol Metab. 1998;83:780-783.

59. Bandeira-Echtler E, Bergerhoff K, Richter B. Levothyroxine or minimally invasive therapies for benign thyroid nodules. Cochrane Database Syst Rev. 2014;(6):CD004098.

60. Gharib H, Papini E, Garber JR. American Association of Clinical Endocrinologists, American College of Endocrinology, and Associazione Medici Endocrinologi medical guidelines for clinical practice for the diagnosis and managmenet of thyroid nodules: 2016 update. Endocr Pract. 2016;22:622-639.

61. Orlander PR, Varghese JM, Freeman LM. What is the prevalence of hypothyroidism in the US? Medscape website. https://www.medscape.com/answers/122393-11267/ what-is-the-prevalence-of-hypothyroidism-in-the-us. Updated March 3, 2021. Accessed March 30, 2021.

62. Mendes D, Alves C, Silverio N, Batel Marquesa F. Prevalence of undiagnosed hypothyroidism in Europe: a systematic review and meta-analysis. Eur Thyroid J. 2019;8: $130-143$.

63. Leung AM, Braverman LE. Consequences of excess iodine. Nat Rev Endocrinol. 2014; $10: 136-142$

64. Martino E, Bartalena L, Bogazzi F, Braverman LE. The effects of amiodarone on the thyroid. Endocr Rev. 2001;22:240-254.

65. Lazarus JH. Lithium and thyroid. Best Pract Res Clin Endocrinol Metab. 2009;23: $723-733$.

66. Tomer Y, Menconi F. Interferon induced thyroiditis. Best Pract Res Clin Endocrinol Metab. 2009;23:703-712

67. Torino F, Barnabei A, Paragliola R, Baldelli R, Appetecchia M, Corsello SM. Thyroid dysfunction as an unintended side effect of anticancer drugs. Thyroid. 2013;23:13451366.

68. Ajjan RA, Weetman AP. The pathogenesis of Hashimoto's thyroiditis: further developments in our understanding. Horm Metab Res. 2015;47:702-710.

69. Keller-Petrot I, Leger J, Sergent-Alaoui A, de Labriolle-Vaylet C. Congenital hypothyroidism: role of nuclear medicine. Semin Nucl Med. 2017;47:135-142.

70. Targovnik HM, Citterio CE, Rivolta CM. Thyroglobulin gene mutations in congenital hypothyroidism. Horm Res Paediatr. 2011;75:311-321.

71. Targovnik HM, Citterio CE, Rivolta CM. Iodide handling disorders (NIS, TPO, TG, IYD). Best Pract Res Clin Endocrinol Metab. 2017;31:195-212.

72. Peterson SJ, Cappola AR, Castro MR. An online survey of hypothyroid patients demonstrates prominent dissatisfaction. Thyroid. 2018;28:707-721.

73. Tariq A, Wert Y, Cheriyat P, Joshi R. Effects of long-term combination LT4 and LT3 therapy for improving hypothyroidism and overall quality of life. South Med J. 2018; 111:363-369.

74. Jonklaas J, Tefera E, Shara N. Short-term time trends in prescribing therapy for hypothyroidism: results of a survey of American Thyroid Association members. Front Endocrinol (Lausanne). 2019;10:31.

75. Volpé R. The management of subacute (DeQuervain's) thyroiditis. Thyroid. 1993;3: 253-255.

76. Felicetta JV. Painful, painless, and postpartum thyroiditis: distinct entities or merely variants? Postgrad Med. 1989;86:269-272.

77. Mygind H. Thyroiditis acute simplex. J Laryngol Rhinol Otol. 1895;9:181-193. 
78. Fatourechi V, Aniszewski JP, Fatourechi GZ, Atkinson EJ, Jacobsen SJ. Clinical features and outcome of subacute thyroiditis in an incidence cohort: Olmsted County, Minnesota, study. J Clin Endocrinol Metab. 2003;88:2100-2105.

79. Fraser R, Harrison RJ. Subacute thyroiditis. Lancet. 1952;1:382-386.

80. Ogawa E, Katsushima Y, Fujiwara I, Iinuma K. Subacute thyroiditis in children: patient report and review of the literature. J Pediatr Endocrinol Metab. 2003;16: $897-900$.

81. Gozariu L, Stroe M, Vladutiu T. Late hypothyroidism following subacute thyroiditis. Exp Clin Endocrinol. 1986;87:48-52.

82. Bartalena L, Bogazzi F, Pecori F, Martino E. Graves' disease occurring after subacute thyroiditis: report of a case and review of the literature. Thyroid. 1996;6: $345-348$.
83. Nyulassy S, Hnilica P, Buc M, Guman M, Hirschová V, Stefanovic J. Subacute (de Quervain's) thyroiditis: association with HLA-Bw35 antigen and abnormalities of the complement system, immunoglobulins and other serum proteins. $J$ Clin Endocrinol Metab. 1977;45:270-274.

84. Kramer AB, Roozendaal C, Dullaart RP. Familial occurrence of subacute thyroiditis associated with human leukocyte antigen-B35. Thyroid. 2004;14:544-547.

85. Vassilopoulou-Sellin R, Sella A, Dexeus FH, Theriault RL, Pololoff DA. Acute thyroid dysfunction (thyroiditis) after therapy with interleukin-2. Horm Metab Res. 1992;24:434-438.

86. Cappelli C, Pirola I, Gandossi E, Formenti AM, Agosti B, Castellano M. Ultrasound findings of subacute thyroiditis: a single institution retrospective review. Acta Radiol. 2014;55:429-433. 